\title{
Development, Validation, and Application of HPLC Method for Quantification of Antihyperuricemic Compounds from Lippia nodiflora in Rat Plasma
}

\section{(๑) $\Theta \Theta$}

\author{
Authors \\ Lee-Chuen Cheng ${ }^{1}$, Vikneswaran Murugaiyah², Kit-Lam Chan ${ }^{3}$
}

\section{Affiliations}

1 School of Pharmacy, University of Reading Malaysia, Persiaran Graduan, Kota Ilmu, Educity, Iskandar Puteri, Johor, Malaysia

2 Discipline of Pharmacology, School of Pharmaceutical Sciences, University of Science Malaysia (Universiti Sains Malaysia), Minden, Penang, Malaysia

3 Discipline of Pharmaceutical Chemistry, School of Pharmaceutical Sciences, University of Science Malaysia (Universiti Sains Malaysia), Minden, Penang, Malaysia

Key words Lippia nodiflora, Verbenaceae, phenylethanoid glycosides, flavonoids, HPLC, pharmacokinetic

received $\quad 03.03 .2019$

revised $\quad 30.05 .2019$

accepted $\quad 06.06 .2019$

Bibliography

DOI https://doi.org/10.1055/a-0955-9505

Planta Med Int Open 2019; 6: e28-e35

(c) Georg Thieme Verlag KG Stuttgart · New York

ISSN 2509-9264

\section{Correspondence}

Prof. Chan Kit Lam

Discipline of Pharmaceutical Chemistry,

School of Pharmaceutical Sciences,

University of Science Malaysia (Universiti Sains Malaysia),

11800 Minden,

Penang,

Malaysia

Tel.: +604/653/2 696, Fax: +604/657/6836

kitlamc@gmail.com $\bigoplus \begin{aligned} & \text { Supplementary Material for this article is available } \\ & \text { online at http://www.thieme-connect.de/products. }\end{aligned}$

\section{ABSTRACT}

An HPLC method for simultaneous determination of arenarioside (1), verbascoside (2), 6-hydroxyluteolin (3), 6-hydroxyluteolin-7-O-glycoside (4), and nodifloretin (5) from Lippia nodiflora in rat plasma was developed and validated. The optimal chromatographic separation was achieved with a gradient mobile phase comprising $0.1 \%$ aqueous acetic acid and acetonitrile. The limit of detection was $78.1 \mathrm{ng} / \mathrm{mL}$ for 3 and $39.1 \mathrm{ng} / \mathrm{mL}$ for the other compounds (signal-to-noise ratio = 3), whereas the limit of quantification was $312.5 \mathrm{ng} / \mathrm{mL}$ for 3 and $156.3 \mathrm{ng} / \mathrm{mL}$ for the other compounds (signal-to-noise ratio $=12$ ). The recovery values of compounds $\mathbf{1} \mathbf{- 5}$ ranged from $89.37-100.92 \%$. Their accuracy values were between 96.48 and $105.81 \%$, while their corresponding precision values were in the range of $0.75-9.06 \%$ for both intraday and inter-day analysis. The method was then applied in the first pharmacokinetic study of 1-5. Following intravenous administration, 1-5 were eliminated slowly from the body with a mean clearance value of $0.11,0.13,0.30,0.09$, and $0.23 \mathrm{~L} / \mathrm{kg} \mathrm{h}$, respectively. Meanwhile, their peak plasma concentration upon oral administration was $8.97,1.07,1.06,0.65$, and $0.38 \mu \mathrm{g} / \mathrm{mL}$, respectively. Compound 3 (5.97\%) exhibited the highest absolute oral bioavailability value, followed by $\mathbf{1}$ (5.22\%), 4 (3.13\%), 2 (2.10\%), and 5 (0.93\%). 


\section{ABBREVIATIONS}

AUC area under the curve (AUC)

$\mathrm{CV}$ coefficient of variation

LOD limit of detection

LOQ limit of quantification

PPC peak plasma concentration

$r^{2} \quad$ coefficient of determination

SEM standard error of the mean

\section{Introduction}

Lippia nodiflora (L.) Michx., also known as Phyla nodiflora (L.) Greene $[1,2]$, is a fast-growing creeping perennial medicinal herb belonging to the Verbenaceae family [3]. It is commonly known as Frog Fruit and has been traditionally used for the treatment of knee joint pain, lithiasis, diuresis, urinary disorders, and swelling [1-5]. The plant is rich in flavonoids [6-9], phenols [10], triterpenoids, and steroids $[11,12]$. Pharmacological studies have shown that the plant possesses a broad array of biological properties, including anti-urolithiasis [13], antihypertensive [14], antioxidant [15], antitumor [16], and anti-inflammatory [17] activity. In addition, our previous study indicated that phenyethanoid glycosides and flavonoids of $L$. nodiflora were promising xanthine oxidase inhibitors [18]. Two phenylethanoid glycosides, namely, arenarioside (1) and verbascoside (2), together with three flavonoids, namely, 6-hydroxyluteolin (3), 6-hydroxyluteolin-7-O-glycoside (4), and nodifloretin (5), isolated from $L$. nodiflora were shown to have an antihyperuricemic effect in potassium oxonate- and hypoxanthine-induced hyperuricemic rats, with 3 being the most active [19].

Due to the promising uric acid-lowering benefit of the phenylethanoid glycosides and flavonoids reported previously [18, 19], the characterization of their bioavailability and pharmacokinetic properties is important for their further development into phytopharmaceuticals. Hitherto, there is no report on the pharmacokinetic data of those antihyperuricemic constituents, except verbascoside. In addition, no analytical method has been developed for the simultaneous determination of the bioavailability and pharmacokinetics of bioactive compounds $\mathbf{1 - 5}$ in rats. The only study found was on the pharmacokinetic of acteoside, also known as verbascoside, from Plantago asiatica or Cistanche deserticola using liquid chromatography-mass spectrometry [20], liquid chromatographytandem mass spectrometry [21,22], or liquid chromatography with amperometric detection [23]. Previously, we developed, validated, and applied an HPLC method for the phytochemical analysis of the antihyperuricemic constituents $\mathbf{1 - 5}$ in the plant samples [24]. In the present study, we aimed at the development of a simple and reliable HPLC method with a UV detection method for the simultaneous determination and quantification of the antihyperuricemic constituents $\mathbf{1 - 5}$ in rat plasma and to apply the method in the pharmacokinetic study of those bioactive compounds in rats after oral and intravenous administration.

\section{Results and Discussion}

In the present study, a simple and reliable HPLC method was developed and validated. It uses UV detection and gradient elution with a mobile phase consisting of $0.1 \%$ aqueous acetic acid (solvent $A$ ) and acetonitrile (solvent $B$ ) for the simultaneous determination and quantification of the five antihyperuricemic constituents in rat plasma with a total run time of approximately 38 min ( $\mathbf{F i g}$. 1b). Solvent $A$ was chosen as it minimized the peak tailing effect related to the dissociation of the hydroxyl group of flavonoids compared to the acid-free solvent. Acid-containing mobile phases are often used for flavonoid separation [25-29]. Since phenylethanoid glycosides and flavonoids exhibited two different sets of UV maxima at 218 and $332 \mathrm{~nm}$, and 282 and $346 \mathrm{~nm}$, respectively, a wavelength of $340 \mathrm{~nm}$ producing a high absorbance for both phenylethanoid glycosides and flavonoids was selected for the HPLC-UV analysis.

The calibration curves for the bioactive compounds in rat plasma were linear over the concentration range investigated with a mean slope ( \pm standard error of mean) of $152.00 \pm 3.75,233.38 \pm 1.25$, $540.33 \pm 3.53,627.10 \pm 5.05$, and $267.93 \pm 5.31$ for $\mathbf{1}, \mathbf{2}, \mathbf{3}, \mathbf{4}$, and $\mathbf{5}$, respectively. In addition, the coefficient of determination for the calibration curve of all five compounds was equal to or greater than 0.9996 ( $\vee$ Table 1). The LOD value was $78.1 \mathrm{ng} / \mathrm{mL}$ for 3 and $39.1 \mathrm{ng} /$ $\mathrm{mL}$ for the rest of the compounds at a signal-to-noise ratio of 3 . On the other hand, the LOQ value for 3 was $312.5 \mathrm{ng} / \mathrm{mL}$, whilst for the rest of the compounds, it was $156.3 \mathrm{ng} / \mathrm{mL}$ at a signal-to-noise ratio of 12 . The recovery of bioactive compounds $\mathbf{1 - 5}$ ranged from 89.37-100.92\% ( Table 2), implying that deproteinization of the plasma with methanol did not result in any substantial loss of the chemical constituents. The accuracy values were between 97.95 and $105.81 \%$ for intraday analysis and between 96.48 and $101.13 \%$ for inter-day analysis. Meanwhile, the corresponding precision values were ranged from 1.15-9.06\% for intraday analysis and ranged from $0.75-7.71 \%$ for inter-day analysis. Both accuracy and precision values indicated that the developed method was reliable and reproducible for the simultaneous determination of the five bioactive chemical constituents in rat plasma.

The developed and validated HPLC method was then successfully applied to simultaneously determine and quantify the 5 antihyperuricemic constituents in the plasma of rats. Rats were administered, either orally $(20 \mathrm{mg} / \mathrm{kg}$ each of $1-5)$ or intravenously $(2 \mathrm{mg} /$ $\mathrm{kg}$ each of 1-5), a mixture of 1-5, consisting of 1, 2, 3, 4, and 5 in a ratio of $1: 1: 1: 1: 1$. The bioactive phenylethanoid glycosides and flavonoids were unambiguously identified as $\mathbf{1 - 5}$ in the rat plasma upon comparison of the retention times with those of their respective standards, as shown in the $>$ Fig. 1. The chromatogram of blank rat plasma is shown in $\mathbf{F i g .} \mathbf{1} \mathbf{a}-\mathbf{c}$ shows the chromatogram of rat plasma spiked with bioactive compounds $\mathbf{1 - 5}$ at a concentration of $5 \mu \mathrm{g} / \mathrm{mL}$ each, whereas $>$ Fig. $\mathbf{1 d}$ shows the chromatogram of rat plasma $1 \mathrm{~h}$ after intravenous administration of the mixture of 1-5 (2 mg/kg each of 1-5).

( $\vee$ Fig. 2a, b) illustrates the mean plasma concentration-time profiles of phenylethanoid glycosides and flavonoids after intravenous administration of the mixture of $\mathbf{1 - 5}$. Following intravenous administration, compounds $\mathbf{1 - 5}$ showed a gradual decline in the plasma concentration starting from the highest concentration at $0 \mathrm{~h}$. Interestingly, the concentrations of phenylethanoid glycosides 

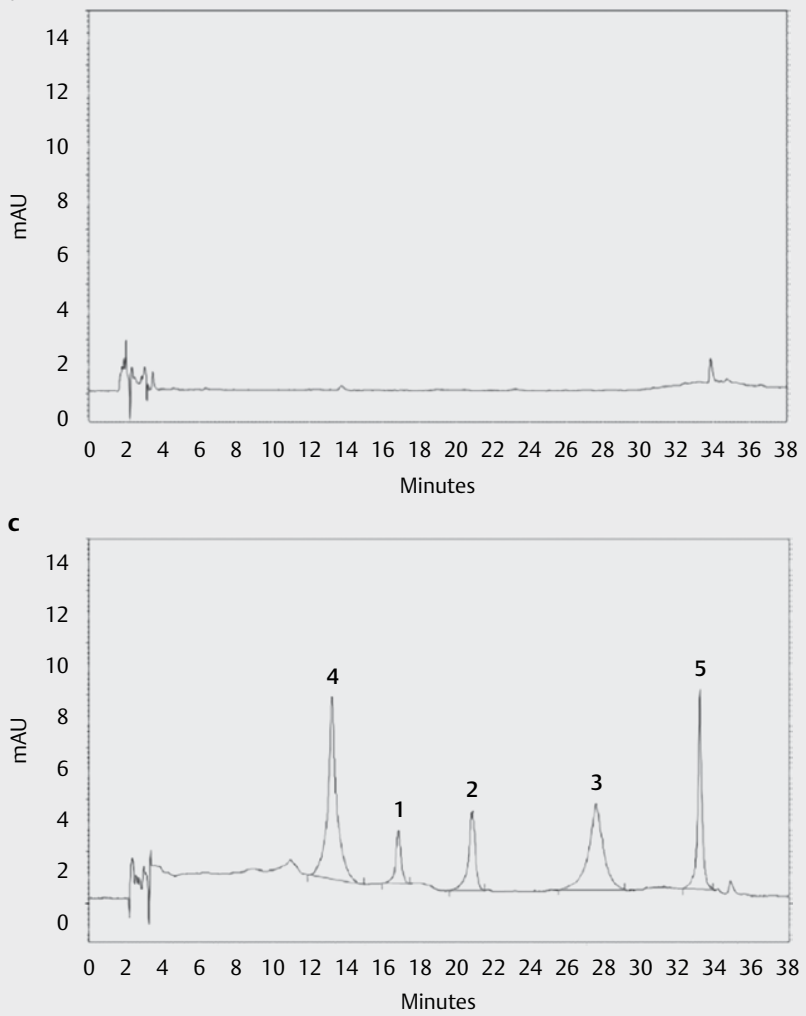

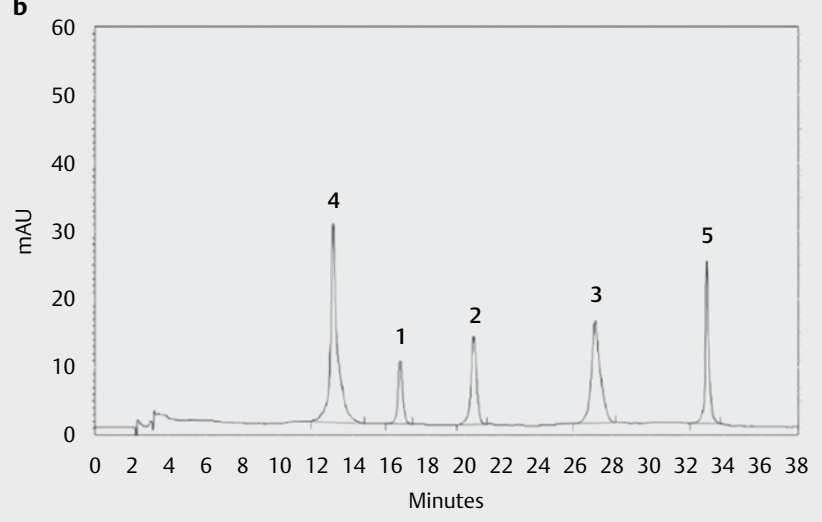

d

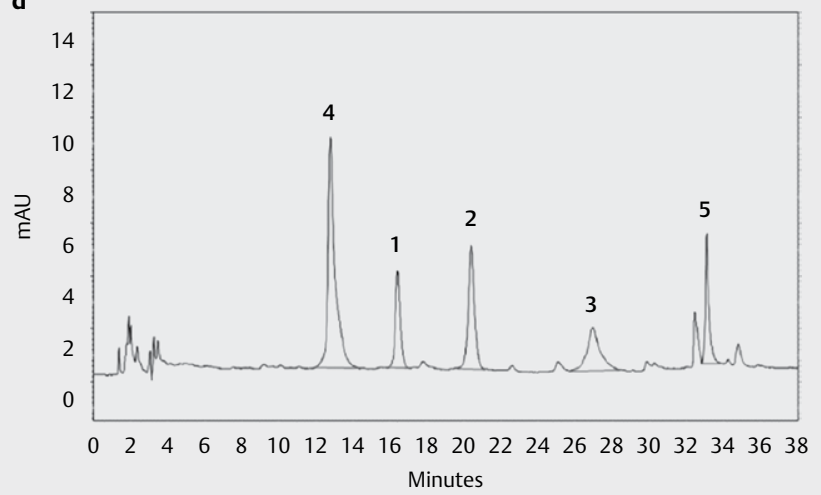

-Fig. 1 HPLC chromatogram from the analysis of arenarioside (1), verbascoside (2), 6-hydroxyluteolin (3), 6-hydroxyluteolin-7-0-glycoside (4), and nodifloretin (5). a Blank rat plasma. b Mixed standards $(10 \mu \mathrm{g} / \mathrm{mL}$ each of 1-5) isolated from L. nodiflora. c Rat plasma spiked with 1-5 (5 $\mathrm{mg} / \mathrm{mL}$ each). $\mathbf{d}$ Rat plasma $1 \mathrm{~h}$ after intravenous administration of the mixture of $\mathbf{1 - 5}(2 \mathrm{mg} / \mathrm{kg}$ each of $\mathbf{1 - 5})$.

- Table 1 Regression equations, correlation coefficients, linear ranges, and limits of detection and quantification of the antihyperuricemic constituents (1-5) of L. nodiflora.

\begin{tabular}{|l|l|l|l|l|l|}
\hline Compound & Regression equation & $\mathbf{r}^{\mathbf{2}}$ & Linear range $\mathbf{( n g} / \mathbf{m L})$ & LOD $(\mathbf{n g} / \mathbf{m L})$ & $\mathbf{L O Q}$ (ng/mL) \\
\hline Arenarioside & $\mathrm{y}=152.00 \mathrm{x}-20.39$ & 0.9999 & $156.3-20000$ & 39.1 & 156.3 \\
\hline Verbascoside & $\mathrm{y}=233.38 \mathrm{x}-58.81$ & 0.9997 & $156.3-20000$ & 39.1 & 156.3 \\
\hline 6-Hydroxyluteolin & $\mathrm{y}=540.33 \mathrm{x}-371.64$ & 0.9996 & $312.5-20000$ & 78.1 & 312.5 \\
\hline 6-Hydroxyluteolin-7-O-glycoside & $\mathrm{y}=627.10 \mathrm{x}-130.44$ & 0.9996 & $156.3-20000$ & 39.1 & 156.3 \\
\hline Nodifloretin & $\mathrm{y}=267.93 \mathrm{x}+59.24$ & 0.9996 & $156.3-20000$ & 39.1 & 156.3 \\
\hline
\end{tabular}

found in the rat plasma after intravenous administration was higher than those of the flavonoids, with 1 exhibiting the highest PPC value of $11.07 \pm 0.93 \mu \mathrm{g} / \mathrm{mL}$, while 2 showed the second highest PPC value of $8.75 \pm 1.10 \mu \mathrm{g} / \mathrm{mL}$, followed by $\mathbf{4}, \mathbf{5}$, and $\mathbf{3}$ with their corresponding PPC values of $8.12 \pm 0.45,5.89 \pm 0.67$, and $4.13 \pm 0.57 \mu \mathrm{g} / \mathrm{mL}$, respectively.

( Fig. 3a, b) illustrates the mean plasma concentration-time profiles of phenylethanoid glycosides and flavonoids after oral administration of the mixture of 1-5. Following oral administration, all five compounds showed a rapid rise, and reached the maximal concentration in the rat plasma with a $\mathrm{T}_{\max }$ ranging from $0.5-$ $0.67 \mathrm{~h}$, indicating that they were rapidly absorbed and entered the blood circulation system. This finding was consistent with an earlier study where a phenylethanoid glycoside, acteoside, was shown to reach its maximal concentration in the rat plasma $(0.1 \mu \mathrm{g} / \mathrm{mL})$ within the first $30 \mathrm{~min}$ after oral administration [21]. It is important to note that 1 showed a distinctively higher concentration in the rat plasma than the rest of the compounds after oral administration, with a PPC value of $8.46 \pm 0.62 \mu \mathrm{g} / \mathrm{mL}$, whereas compound 5 showed the lowest concentration in the rat plasma after oral administration with a PPC value of $0.38 \pm 0.01 \mu \mathrm{g} / \mathrm{mL}$. The oral administration profile pattern displayed by 2 was very similar to that displayed by $\mathbf{3}$, as indicated by their close mean maximum plasma concentration values.

- Table 3 summarizes the pharmacokinetic parameters of the bioactive compounds $\mathbf{1 - 5}$ in rat plasma after intravenous or oral administration of the mixture of $\mathbf{1 - 5}$, comprising $2 \mathrm{mg} / \mathrm{kg}$ each of $\mathbf{1 - 5}$ or $20 \mathrm{mg} / \mathrm{kg}$ each of $\mathbf{1 - 5}$, respectively. Following intravenous 
- Table 2 Recovery and intraday and inter-day precision and accuracy values of the bioactive compounds (1-5) of $L$. nodiflora.

\begin{tabular}{|c|c|c|c|c|c|c|}
\hline \multirow[t]{2}{*}{ Concentration (ng/mL) } & \multicolumn{2}{|c|}{ Recovery $(n=3)$} & \multicolumn{2}{|c|}{ Intraday $(n=6)$} & \multicolumn{2}{|c|}{ Inter-day $(n=6)$} \\
\hline & Mean (\%) & $\begin{array}{l}\text { Mean } \\
(\mathrm{CV}, \%)\end{array}$ & $\begin{array}{l}\text { Accuracy ( } \% \text { of } \\
\text { true value) }\end{array}$ & $\begin{array}{l}\text { Precision } \\
\text { (CV, \%) }\end{array}$ & $\begin{array}{l}\text { Accuracy ( } \% \text { of } \\
\text { true value) }\end{array}$ & $\begin{array}{l}\text { Precision } \\
\text { (CV, \%) }\end{array}$ \\
\hline \multicolumn{7}{|l|}{ Arenarioside } \\
\hline 156.3 & 89.37 & 7.43 & 99.77 & 8.09 & 99.68 & 4.66 \\
\hline 625 & 92.53 & 3.50 & 100.82 & 4.98 & 98.58 & 6.67 \\
\hline 2500 & 93.88 & 3.61 & 99.14 & 4.26 & 96.48 & 4.06 \\
\hline 5000 & 96.27 & 5.24 & 101.79 & 2.08 & 99.42 & 3.92 \\
\hline 10000 & 95.19 & 4.20 & 105.81 & 3.32 & 101.13 & 2.48 \\
\hline 20000 & 96.27 & 4.81 & 99.45 & 2.35 & 100.20 & 2.22 \\
\hline \multicolumn{7}{|l|}{ Verbascoside } \\
\hline 156.3 & 91.11 & 4.30 & 99.55 & 9.06 & 100.81 & 6.69 \\
\hline 625 & 94.67 & 7.88 & 101.53 & 3.39 & 97.15 & 7.71 \\
\hline 2500 & 94.56 & 3.72 & 99.06 & 1.89 & 100.10 & 3.68 \\
\hline 5000 & 92.83 & 6.61 & 99.14 & 2.18 & 98.99 & 5.81 \\
\hline 10000 & 93.94 & 3.85 & 99.93 & 4.66 & 99.95 & 1.68 \\
\hline 20000 & 96.81 & 2.82 & 99.36 & 1.76 & 99.36 & 1.94 \\
\hline \multicolumn{7}{|l|}{ 6-Hydroxyluteolin } \\
\hline 312.5 & 97.33 & 6.57 & 98.95 & 5.10 & 98.96 & 4.84 \\
\hline 625 & 91.79 & 6.42 & 100.73 & 5.08 & 99.64 & 5.93 \\
\hline 2500 & 90.57 & 4.78 & 100.93 & 1.53 & 99.71 & 1.47 \\
\hline 5000 & 92.66 & 6.14 & 98.53 & 3.86 & 100.27 & 5.71 \\
\hline 10000 & 90.00 & 2.67 & 100.91 & 2.71 & 99.57 & 2.70 \\
\hline 20000 & 92.73 & 3.85 & 99.44 & 3.70 & 99.99 & 2.50 \\
\hline \multicolumn{7}{|c|}{ 6-Hydroxyluteolin-7-O-glycoside } \\
\hline 156.3 & 97.47 & 1.43 & 99.91 & 2.15 & 99.21 & 2.55 \\
\hline 625 & 100.92 & 4.55 & 99.43 & 3.81 & 100.53 & 5.48 \\
\hline 2500 & 96.66 & 2.24 & 102.27 & 2.06 & 100.70 & 2.70 \\
\hline 5000 & 92.06 & 3.14 & 100.30 & 1.78 & 99.30 & 1.84 \\
\hline 10000 & 95.41 & 1.11 & 98.94 & 1.37 & 99.11 & 1.42 \\
\hline 20000 & 97.26 & 2.13 & 100.27 & 1.15 & 99.67 & 0.75 \\
\hline \multicolumn{7}{|l|}{ Nodifloretin } \\
\hline 156.3 & 94.38 & 3.11 & 99.82 & 4.10 & 99.75 & 4.15 \\
\hline 625 & 93.99 & 5.51 & 100.44 & 4.71 & 100.84 & 4.96 \\
\hline 2500 & 91.70 & 2.85 & 101.18 & 4.40 & 99.48 & 3.76 \\
\hline 5000 & 94.02 & 2.90 & 103.54 & 1.66 & 99.35 & 5.89 \\
\hline 10000 & 93.54 & 6.62 & 97.95 & 5.05 & 99.95 & 2.29 \\
\hline 20000 & 92.58 & 3.44 & 102.63 & 3.07 & 99.12 & 1.70 \\
\hline
\end{tabular}

administration, 3 exhibited the highest $V_{d}$ value, implying that a greater amount of $\mathbf{3}$ was distributed into the tissue compartment compared to the other compounds. Remarkably, 4 exhibited the lowest mean clearance value, indicating that it has been cleared from the body slower than the other compounds. With regards to this, $\mathbf{4}$ had the longest corresponding half-life and the largest AUC value, suggesting that the tissue distributed compound 4 was retained in tissue compartment and eliminated slowly, despite its relatively small volume of distribution value. Thus, while 1, 2, 3, and 5 showed a gradual decline to 0 at $24 \mathrm{~h}, \mathbf{4}$ did not decline to 0 and still could be detected even at $24 \mathrm{~h}$ after both oral and intravenous administration.
Following oral administration, 1 showed the highest mean $\mathrm{C}_{\max }$ and AUC values, despite having the largest molecular size compared to the other compounds. In contrast, $\mathbf{5}$ exhibited the lowest mean $C_{\text {max }}$ and $A U C$ values, suggesting that its absorption after oral administration was incomplete. In general, the plasma levels of all 5 compounds given orally were much lower than those of the intravenous administration, even though their oral doses were 10 times higher than their intravenous doses, indicating that their oral bioavailability was low and incomplete. The low oral bioavailability might be due to the first-pass metabolism reducing the concentration of the compound before it reaches the systemic circulation [30]. Nevertheless, it is interesting to note that the most potent 


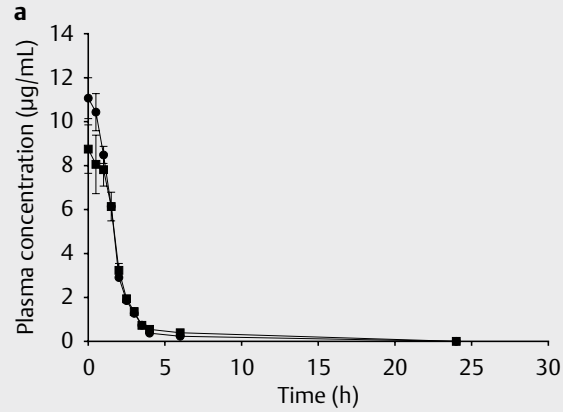

- arenarioside (1) - verbascoside (1)

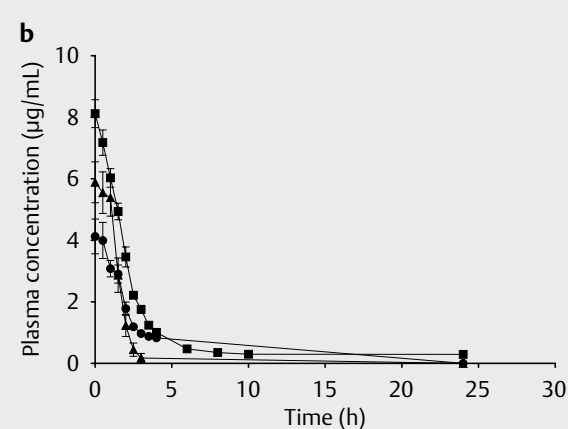

- 6-hydroxyluteolin (3) -6-hydroxyluteolin$\star$ nodifloretin (5) -6-hydroxyluteolin-
7-O-glycoside (4)

- Fig. 2 Mean plasma concentration-time profiles of a phenylethanoid glycosides (1 and $\mathbf{2}$ ) and $\mathbf{b}$ flavonoids (3-5) after intravenous administration of the mixture of 1-5 $(2 \mathrm{mg} / \mathrm{kg}$ each of $\mathbf{1 - 5})$; mean \pm SEM, $n=6$.

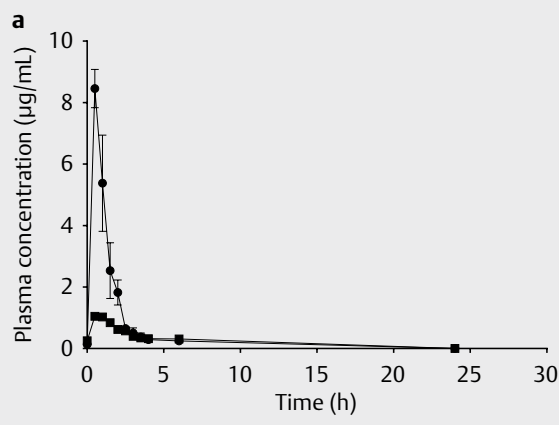

- $\operatorname{arenarioside~}(\mathbf{1}) \rightarrow$ verbascoside $(1)$

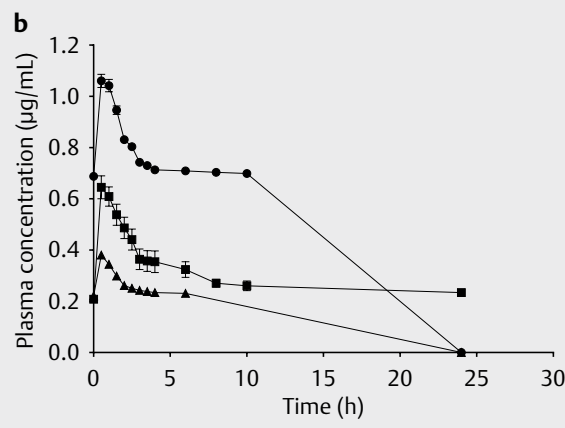

- 6-hydroxyluteolin (3) -6-hydroxyluteolin$\rightarrow$ nodifloretin (5) 7-O-glycoside (4)

Fig. 3 Mean plasma concentration-time profiles of a phenylethanoid glycosides (1 and $\mathbf{2}$ ) and $\mathbf{b}$ flavonoids (3-5) after oral administration of the mixture of $1-5(20 \mathrm{mg} / \mathrm{kg}$ each of $1-5)$; mean \pm SEM, $n=6$.

- Table 3 Pharmacokinetic parameters of the antihyperuricemic constituents (1-5) in rat plasma after intravenous ( $2 \mathrm{mg} / \mathrm{kg}$ of each compound) or oral $(20 \mathrm{mg} / \mathrm{kg}$ of each compound) administration of the mixture of $\mathbf{1 - 5}$.

\begin{tabular}{|l|c|c|c|c|c|}
\hline Parameters & $\mathbf{1}$ & $\mathbf{2}$ & $\mathbf{3}$ & $\mathbf{4}$ & $\mathbf{5}$ \\
\hline Intravenous administration & & & & & \\
\hline $\mathrm{AUC}_{0-\infty}(\mu \mathrm{g} \mathrm{h} / \mathrm{mL})$ & $18.69 \pm 0.79$ & $16.72 \pm 1.67$ & $6.98 \pm 0.70$ & $22.80 \pm 0.59$ & $9.52 \pm 1.30$ \\
\hline$K_{\mathrm{e}}\left(\mathrm{h}^{-} \mathrm{l}\right)$ & $0.76 \pm 0.01$ & $0.64 \pm 0.04$ & $0.45 \pm 0.05$ & $0.15 \pm 0.01$ & $1.35 \pm 0.08$ \\
\hline$t_{1 / 2}(\mathrm{~h})$ & $0.92 \pm 0.01$ & $1.11 \pm 0.08$ & $1.65 \pm 0.24$ & $4.75 \pm 0.10$ & $0.53 \pm 0.03$ \\
\hline$V_{\mathrm{d}}(\mathrm{L} / \mathrm{kg})$ & $0.14 \pm 0.01$ & $0.21 \pm 0.03$ & $0.76 \pm 0.18$ & $0.60 \pm 0.03$ & $0.17 \pm 0.02$ \\
\hline $\mathrm{CL}(\mathrm{L} / \mathrm{kg} \mathrm{h})$ & $0.11 \pm 0.01$ & $0.13 \pm 0.01$ & $0.30 \pm 0.03$ & $0.09 \pm 0.01$ & $0.23 \pm 0.03$ \\
\hline Oral administration & & & & $7.13 \pm 0.44$ & $0.89 \pm 0.02$ \\
\hline $\mathrm{AUC} C_{0-\infty}(\mu \mathrm{g} \mathrm{h} / \mathrm{mL})$ & $9.76 \pm 1.65$ & $3.51 \pm 0.19$ & $4.17 \pm 0.05$ & $0.65 \pm 0.04$ & $0.38 \pm 0.01$ \\
\hline$C_{\max }(\mu \mathrm{g} / \mathrm{mL})$ & $8.97 \pm 0.79$ & $1.07 \pm 0.07$ & $1.06 \pm 0.03$ & 0.03 & $0.50 \pm 0.01$ \\
\hline$T_{\max }(\mathrm{h})$ & $0.67 \pm 0.11$ & $0.67 \pm 0.11$ & $0.50 \pm 0.01$ & $0.58 \pm 0.08$ & \\
\hline
\end{tabular}

antihyperuricemic constituent 3 has the highest estimated absolute oral bioavailability value of $5.97 \%$, followed by $\mathbf{1}, \mathbf{4}, \mathbf{2}$, and $\mathbf{5}$, with estimated absolute oral bioavailability values of 5.22, 3.13, 2.10 , and $0.93 \%$, respectively.
In conclusion, the pharmacokinetic study unveiled that the oral bioavailability of the bioactive compounds of $L$. nodiflora was low and need to be improved, thus, further study for the development of phenylethanoid glycoside and flavonoid formulations to enhance their oral bioavailability is warranted. 


\section{Materials and Methods}

\section{Chemicals and reagents}

Deionized water was prepared using a Maxima ultra-pure water purifier system purchased from Elga. HPLC grade methanol and acetonitrile were purchased from Merck. Sephadex LH-20 (No. 170090-02) was purchased from GE Healthcare. Sodium heparin was purchased from Acros Organic. Acetic acid was purchased from Systerm ChemAR.

\section{Isolation of bioactive compounds}

Frog Fruit [L. nodiflora (L.) Michx.] plants were collected from Seremban, Negeri Sembilan, Malaysia. The plant was authenticated by Dr. Rahmad Zakaria, a botanist of the Herbarium Unit, School of Biological Sciences, University of Science Malaysia (Universiti Sains Malaysia). A voucher specimen (No. 11594) was deposited at the same unit. The 5 antihyperuricemic constituents, namely, arenarioside (1), verbascoside (2), 6-hydroxyluteolin (3), 6-hydroxyluteolin-7-O-glycoside (4), and nodifloretin (5) (> Fig. 4), were isolated from the bioactive fraction of $L$. nodiflora following the protocol described previously [19] and were used as marker compounds for the method validation and quantification of rat plasma samples. The purity of the compounds was determined using an Agilent 1120 Compact LC system equipped with a variable wavelength photometric detector and Agilent EZ-Chrom Elite Compact Software (Agilent Technologies) [24]. The purities were found to be 97.71, $98.19,96.25,97.30$, and $97.36 \%$ for $\mathbf{1}, \mathbf{2}, \mathbf{3}, \mathbf{4}$, and $\mathbf{5}$, respectively.

\section{Instrumentation}

The HPLC system consisted of an Agilent 1120 Compact LC system equipped with a variable wavelength photometric detector set at a wavelength of $340 \mathrm{~nm}$, and Agilent EZ-Chrom Elite Compact Software (Agilent Technologies). An Inertsil ODS-3 $(4.6 \mathrm{~mm}$ i.d. $\times 250 \mathrm{~mm}$, GL Ssciences Inc.) column pre-connected with an Inertsil ODS-3 guard column ( $4.6 \mathrm{~mm}$ i.d. $\times 50 \mathrm{~mm}$, GL Sciences Ins.) was used for the chromatographic separation. The mobile phase consisting of $0.1 \%$ aqueous acetic acid (A) and acetonitrile (B) was delivered with gradient elution at a flow rate of $1.0 \mathrm{~mL} / \mathrm{min}$ at room temperature. The gradient elution was programmed as follows: 0-25 min, 15\% B; 25-30 min, 20\% B; 30-35 min, 36\% B; 35-38 min, $15 \% \mathrm{~B}$. This was followed by a 12 -min equilibration period prior to the injection of each sample [24].

\section{Sample preparation}

Frozen plasma samples were thawed at the room temperature. A plasma sample $(100 \mu \mathrm{L})$ was transferred into a $1.5-\mathrm{mL}$ microcentrifuge tube and proteins were precipitated by adding $100 \mu \mathrm{L}$ of methanol. The mixture was vortexed for 1 min using an Autovortex SA6 (Stuart Scientific) and then centrifuged at $7711 \times \mathrm{g}$ using a Micro 12 centrifuge (Hanil Science Industrial) for $15 \mathrm{~min}$. The supernatant was transferred into a new microcentrifuge tube and $20 \mu \mathrm{L}$ were used for injection.

\section{Limit of detection, limit of quantification, and linearity}

The calibration curves were constructed by plotting peak areas against the concentrations of the analyte prepared at $312.5,625$, $2500,5000,10000$, and $20000 \mathrm{ng} / \mathrm{mL}$ for 3 and 156.3, 625, 2500 , 5000,10000 , and $20000 \mathrm{ng} / \mathrm{mL}$ for 1, 2, 4 and 5. The linearity of the curves was evaluated by linear regression analysis and was expressed as the $r^{2}$. LOD and LOQ were determined by triplicate analysis of a series of successive twofold dilutions of the stock solutions. The LOD was defined as the lowest concentration that the analytical system can reliably differentiate from the background level and was calculated based on a signal-to-noise ratio of 3:1. The LOQ was defined as the lowest quantifiable concentration on the calibration curve and was calculated based on a signal-to-noise ratio of 12:1 [24, 31, 32].

\section{Method validation}

The method was validated through intraday and inter-day analysis of precision and accuracy according to the International Conference on Harmonisation guidelines [33]. The intraday accuracy and precision were determined for each compound by evaluating six replicate measurements of each concentration on a single day, while the inter-day accuracy and precision were determined by assessing measurements of each concentration over 6 consecutive days [24]. The recovery of the direct extraction method using methanol was calculated by comparing the peak area of the compounds after extraction with those of the compounds dissolved in the methanol at a similar concentration [24]. Accuracy was expressed as a percentage of true value, while precision was expressed as a CV [24].

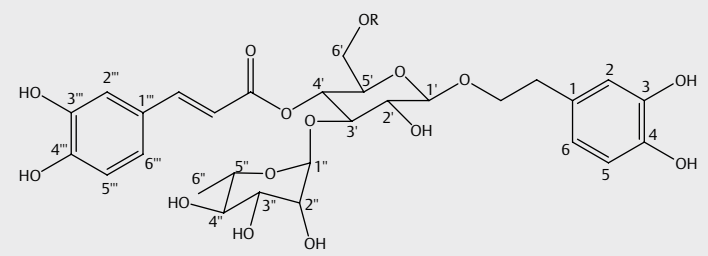

1: $R=$ Xylosyl

$2: \mathrm{R}=\mathrm{H}$

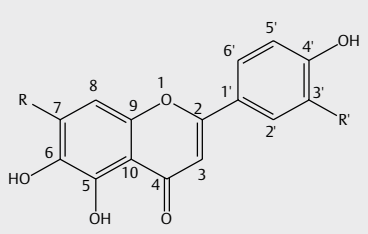

3: $\mathrm{R}=\mathrm{OH}, \mathrm{R}^{\prime}=\mathrm{OH}$

4: $\mathrm{R}=\mathrm{O}-\mathrm{Glu}, \mathrm{R}^{\prime}=\mathrm{OH}$

5: $\mathrm{R}=\mathrm{OH}, \mathrm{R}^{\prime}=\mathrm{OMe}$

- Fig. 4 The chemical structures of antihyperuricemic phenylethanoid glycosides (1 and $\mathbf{2}$ ) and flavonoids (3-5) isolated from L. nodiflora. 


\section{Animals}

Male Sprague-Dawley rats (260-300 g) were obtained from the Animal Research and Service Centre of the University of Science Malaysia (Universiti Sains Malaysia) and were kept in the animal transit room of the School of Pharmaceutical Sciences, University of Science Malaysia (Universiti Sains Malaysia), Penang, Malaysia. They were maintained on a 12-h light/dark cycle at a room temperature of $25^{\circ} \mathrm{C}$ and were allowed free access to standard food pellets and tap water. The animals were acclimatized for 1 week prior to experimentation. The study protocol was approved by the Animal Ethics Committee, University of Science Malaysia (Universiti Sains Malaysia), Penang, Malaysia [USM/Animal Ethics Approval/2013/(89)(478)] and was in accordance with institutional guidelines (Guideline for the Care and Used of Animals for Scientific Purposes, USM) and international policies (Public Health Service Policy on Humane Care and Use of Laboratory Animal, and Guide for the Care and Use of Laboratory Animals) [34, 35].

\section{Pharmacokinetic study}

The animals were divided into two groups of three each and the study was conducted according to a two-way crossover study design. Food, but not water, was withheld overnight prior to the experimentation. Group $1(n=3)$ was intravenously injected with a mixture comprising bioactive compounds $\mathbf{1 - 5}(2 \mathrm{mg} / \mathrm{kg}$ of each compound), while group $2(n=3)$ was orally administered with a mixture consisting of bioactive compounds $\mathbf{1 - 5}(20 \mathrm{mg} / \mathrm{kg}$ of each compound). After a washout period of 2 weeks, the animals from group 1 were orally administered with a mixture of $\mathbf{1 - 5}$ comprising $20 \mathrm{mg} / \mathrm{kg}$ each of $\mathbf{1 - 5}$, while those from group 2 were intravenously injected with another mixture of $\mathbf{1 - 5}$ consisting of $2 \mathrm{mg} / \mathrm{kg}$ each of 1-5. For both routes of drug administration, the mixture of 1-5 was prepared in $20 \%$ of Tween 20 aqueous solution. The volume for intravenous injection and oral administration was $1 \mathrm{~mL} / \mathrm{kg}$ and $5 \mathrm{~mL} / \mathrm{kg}$ of body weight, respectively. The animals were placed in animal restraining cage during blood collection and the blood samples of $0.5 \mathrm{~mL}$ were collected by the tail nipping method into a sodium heparin-coated microcentrifuge tube at $0,0.5,1,1.5,2$, $2.5,3,3.5,4,6,8,10$, and $24 \mathrm{~h}$ after drug administration. The blood samples were centrifuged at $4000 \times \mathrm{g}$ for $15 \mathrm{~min}$ and the resulting plasma samples were kept frozen at $-20^{\circ} \mathrm{C}$ prior to analysis [31].

\section{Data analysis}

The following pharmacokinetic parameters were calculated: The elimination rate constant $\left(\mathrm{K}_{\mathrm{e}}\right)$ was calculated from the slope of plasma concentration versus time curve. The slope of the curve was equal to $\mathrm{K}_{\mathrm{e}} / 2.303$. The elimination half-life $\left(\mathrm{t}_{1 / 2}\right)$ was determined as $0.693 / K_{e}$, while the volume of distribution $\left(V_{d}\right)$ was estimated using the equation $\mathrm{V}_{\mathrm{d}}=$ dose $/ \mathrm{K}_{\mathrm{e}} \times \mathrm{AUC}_{0-\infty}$. The theoretical concentration at time zero $\left(C_{0}\right)$ was calculated as the intercept of the semilogarithmic concentration-time curve. The area under the plasma concentration-time curve to infinity $\left(\mathrm{AUC}_{0_{-\infty}}\right)$ was determined by combining the area from time zero to the last sampling time $\left(\mathrm{AUC}_{0-\mathrm{t}}\right)$ with the area from the last sampling time to infinity $\left(A \cup C_{t-\infty}\right)$, whereby the trapezoidal rule was applied. Total body clearance $(C L)$ was estimated from the relationship $C L=$ dose/ $A \cup C_{0-\infty}$. Peak concentration $\left(C_{\max }\right)$ and time to reach $C_{\max }\left(T_{\max }\right)$ following oral administration were obtained directly from the plas- ma concentration-time plots. The absolute oral bioavailability $(F)$ was calculated as the ratio of the dose-normalized AUC (AUC/dose) after oral and intravenous administration. The results are expressed as the mean \pm SEM.

\section{Supporting Information}

The ${ }^{1} \mathrm{H}$ - and ${ }^{13} \mathrm{C}-\mathrm{NMR}, \mathrm{MS}, \mathrm{UV}$, and IR data of 1-5 are available as Supporting Information.

\section{Acknowledgements}

The authors would like to thank the University of Science Malaysia (Universiti Sains Malaysia) for providing a grant (No. 1001/PFARMASI/846067) under a postgraduate research grant scheme (PRGS) to support this study. C. L. C. gratefully acknowledges the financial support by the MyPhD Scholarship from the Ministry of Education of Malaysia. C. L. C. would like to thank Dr. Liew Kok Fui for his contribution to this study.

\section{Conflict of Interest}

The authors declare that there is no conflict of interest regarding the publication of this paper.

\section{References}

[1] Khare CP. Indian medicinal plants: An illustrated dictionary. New York, USA: Springer-Verlag; 2007: 480-481

[2] Umberto Quattrocchi FLS CRC world dictionary of medicinal and poisonous plants. common names, scientific names, eponyms, synonyms, and etymology. Boca Raton, Florida, USA: Taylor and Francis Group, LLC; 2012: 2895-2896

[3] Sharma RA, Singh R. A review on Phyla nodiflora Linn.: A wild wetland medicinal herb. Int J Pharm Sci Rev Res 2013; 20: 57-63

[4] Narendra ND, Bhupesh CN, Rameswara RG, Bastipati S. Evaluation of hepatoprotective activity of Phyla nodiflora L. against $\mathrm{CCl}_{4}$ induced hepatotoxicity. Int J Innov Drug Disc 2012; 2: 16-21

[5] Yang XR, Chen AM, Ma YF, Gao Y, Gao ZM, Fu BY, Sun F, Qiao JL, Li Q, Wan SQ, Werner H, Chuang YF, Zhu XS. Traditional Chinese medicine: A manual from A-Z: Symptoms, therapy, and herbal remedies. Heidelberg, New York, USA: Springer-Verlag; Berlin: 2003 340:

[6] Barua AK, Chakrabarti P, Sanyal PK. Structure of nodifloretin - new flavone from Lippia nodiflora. Trans Bose Res Inst (Calcutta) 1971; 33-34: 5-8

[7] Barnabas C, Gunasingh G, Nagarajan S. Flavonoids from the flowers of Phyla nodiflora Linn. Indian J Chem, Sect B 1980; 19B: 822

[8] Sudha A, Srinivasan P. Bioassay-guided isolation and antioxidant evaluation of flavonoid compound from aerial parts of Lippia nodiflora. BioMed Res Int 2014; 2014; 1-10

[9] Tomás-Barberán FA, Harborne JB, Self R. Twelve 6-oxygenated flavone sulphates from Lippia nodiflora and L. canescens. Phytochemistry 1987; 26: 2281-2284

[10] Khalil AT, Lahloub MF, Salama OM. Phenolic compounds from Lippia nodiflora. J Pharm Sci 1995; 11: 256-265

[11] Siddiqui BS, Ahmad F, Sattar F, Begum S. Chemical constituents from the aerial parts of Lippia nodiflora Linn. Arch Pharm Res 2007; 30: $1507-1510$ 
[12] Siddiqui BS, Ahmed F, Ali SK, Perwaiz S, Begum S. Steroidal constituents from the aerial parts of Lippia nodiflora Linn. Nat Prod Res 2009; 23: 436-441

[13] Dodoala S, Diviti R, Koganti B, Prasad KVSRG. Effect of ethanolic extract of Phyla nodiflora (Linn.) Greene against calculi producing diet induced urolithiasis. Indian J Nat Prod Resour 2010; 1: 314-321

[14] Gadhvi R, Mishra G], Reddy MN, Nivserkar M. Antihypertensive efficacy of Lippia nodiflora - whole plant on uninephrectomized doca - salt hypertensive rats. IOSR J Pharm 2012; 2: 24-28

[15] Shukla S, Saluja AK, Pandya SS. In-vitro antioxidant activity of aerial parts of Lippia nodiflora Rich. Pharmacologyonline 2009; 2: 450-459

[16] Durairaj A, Mazumder UK, Gupta M, Selvan VT. Effect on inhibition of proliferation and antioxidant enzyme level of Lippia nodiflora in EAC cell line treated mice. J Complement. Integr Med 2009; 6: 713-714

[17] Balakrishnan G, Janakarajan L, Balakrishnan A, Lakshmi BS. Molecular basis of the anti-inflammatory property exhibited by cyclopentano phenanthrenol isolated from Lippia nodiflora. Immunol Invest 2010; 39: 713-739

[18] Cheng LC, Murugaiyah V, Chan KL. In vitro xanthine oxidase inhibitory studies of Lippia nodiflora and isolated flavonoids and phenylethanoid glycosides as potential uric acid-lowering agents. Nat Prod Commun 2015; 10: 945-948

[19] Cheng LC, Murugaiyah V, Chan KL. Flavonoids and phenylethanoid glycosides from Lippia nodiflora as promising antihyperuricemic agents and elucidation of their mechanism of action. J Ethnopharmacol 2015; 176: 485-493

[20] Li Y, Gan L, Li GQ, Deng L, Zhang X, Deng YL. Pharmacokinetics of plantamajoside and acteoside from Plantago asiatica in rats by liquid chromatography-mass spectrometry. J Pharm Biomed Anal 2014; 89: 251-256

[21] Wu YT, Lin LC, Sung JS, Tsai TH. Determination of acteoside in Cistanche deserticola and Boschniakia rossica and its pharmacokinetics in freely-moving rats using LC-MS/MS. J Chromatogr B 2006; 844: 89-95

[22] Zhang W, Huo SX, Wen YL, Xing H, Zhang Q, Li N, Zhao D, Sun XL, Xu J, Yan M, Chen XJ. Pharmacokinetics of acteoside following single dose intragastric and intravenous administrations in dogs. Chin J Nat Med 2015; 13: 634-640

[23] Wu YT, Tsai TR, Lin LC, Tsai TH. Liquid chromatographic method with amperometric detection to determine acteoside in rat blood and brain microdialysates and its application to pharmacokinetic study. J Chromatogr B 2007; 853: 281-286

[24] Cheng LC, Murugaiyah V, Chan KL. Developing a validated HPLC method for the phytochemical analysis of antihyperuricemic phenylethanoid glycosides and flavonoids in Lippia nodiflora. Nat Prod Commun 2017; 12: 1681-1684
[25] Chen HJ, Inbaraj BS, Chen BH. Determination of phenolic acids and flavonoids in Taraxacum formosanum Kitam by liquid chromatography tandem mass spectrometry coupled with a post-column derivatization technique. Int J Mol Sci 2012; 13: 260-285

[26] Kao TH, Huang SC, Inbaraj BS, Chen BH. Determination of flavonoids and saponins in Gynostemma pentaphyllum (Thunb.) Makino by liquid chromatography mass spectrometry. Anal Chim Acta 2008; 626: 200-211

[27] Inbaraj BS, Lu H, Kao TH, Chen BH. Simultaneous determination of phenolic acids and flavonoids in Lycium barbarum Linnaeus by HPLC-DAD-ESI-MS. J Pharm Biomed Anal 2010; 51: 549-556

[28] Tuszyńska M. Validation of the analytical method for the determination of flavonoids in broccoli. J Hort Res 2014; 22: 131-140

[29] Zu YG, Li CY, Fu Y], Zhao C]. Simultaneous determination of catechin, rutin, quercetin kaempferol and isorhamnetin in the extract of sea buckthorn (Hippophae rhamnoides L.) leaves by RP-HPLC with DAD. J Pharm Biomed Anal 2006; 41: 714-719

[30] Thilakarathna SH, Vasantha Rupasinghe HP. Flavonoid bioavailability and attempts for bioavailability enhancement. Nutrients 2013; 5 : 3367-3387

[31] Murugaiyah V, Chan KL. Analysis of lignans from Phyllanthus niruri L. in plasma using a simple HPLC method with fluorescence detection and its application in a pharmacokinetic study. J Chromatogr B 2007; 852: 138-144

[32] Sun DQ, Xue AY, Wu J, Zhang B, Yu JL, Li Q, Sun C. Simultaneous determination of acetylpuerarin and puerarin in rat plasma by liquid chromatography-tandem mass spectrometry: Application to a pharmacokinetic study following intravenous and oral administration. J Chromatogr B 2015; 995-996: 24-30

[33] ICH Harmonised Tripartite Guidelines. Validation of analytical procedures: Text and methodology Q2(R1), International Conference on Harmonisation $(\mathrm{ICH})$ of technical requirements for registration of pharmaceuticals for human use, Current Step 4 version, Parent guideline dated 27 October 1994 (Complementary guidelines on methodology dated 6 November 1996 incorporated in November 2005); Available at https://www.ich.org/fileadmin/Public_Web_Site/ ICH_Products/Guidelines/Quality/Q2_R1_Guideline.pdf Acessed 7 Feb 2019)

[34] National Research Council (NRC). Guide for the care and use of laboratory animals. seventh ed., Institute of Laboratory Animal Resources, Commission on Life Sciences. Washington, D.C: National Academy Press; 1996: 1-125

[35] Public Health Service (PHS). Human Health Research Act.1985 revised Public health service policy on humane care and use of laboratory animals. Bethesda, Maryland, US: US: Department of Health and Human Services, National Institute of Health; 1996: 99-158 